\title{
Potential for Lead Release from Lead-Immobilized Animal Manure Compost in Rhizosphere Soil of Shooting Range
}

\author{
Masahiko Katoh, ${ }^{1,2}$ Wei Lu, ${ }^{3}$ and Takeshi Sato ${ }^{2}$ \\ ${ }^{1}$ Department of Agricultural Chemistry, School of Agriculture, Meiji University, 1-1-1 Higashi-Mita, Tama-ku, \\ Kanagawa 214-8571, Japan \\ ${ }^{2}$ Department of Civil Engineering, Faculty of Engineering, Gifu University, 1-1 Yanagido, Gifu 501-1193, Japan \\ ${ }^{3}$ Department of Civil Engineering, Graduate School of Engineering, Gifu University, 1-1 Yanagido, Gifu 501-1193, Japan
}

Correspondence should be addressed to Masahiko Katoh; mkatoh@meiji.ac.jp

Received 29 April 2016; Revised 12 July 2016; Accepted 17 July 2016

Academic Editor: Rafael Clemente

Copyright ( 2016 Masahiko Katoh et al. This is an open access article distributed under the Creative Commons Attribution License, which permits unrestricted use, distribution, and reproduction in any medium, provided the original work is properly cited.

\begin{abstract}
This study aimed to clarify the magnitude of lead release from lead-sorbed animal manure compost (AMC) in rhizosphere soil compared with nonplanted soil of shooting range. The presence of buckwheat caused reduction in rhizosphere soil $\mathrm{pH}$ and enhancement in the level of water-soluble organic carbon compared with those of nonplanted soil. In addition, the presence of buckwheat altered the lead phases and increased the relative amount of the soluble exchangeable fraction, resulting in increase in the $\mathrm{CaCl}_{2}$-soluble lead level. In contrast, the presence of Guinea grass did not change the lead bioavailability or phases compared with nonplanted soil. Lead release tests in solution showed that between solution $\mathrm{pH} 5$ and solution $\mathrm{pH} 7$ the amount of lead released from the compost was higher in the rhizosphere soil of buckwheat than in nonplanted soil, whereas there was no significant difference between the rhizosphere soil of Guinea grass and nonplanted soil. These results suggest that the increase in the quantity of exchangeable lead resulting from the rhizosphere effect induces lead immobilized by the AMC to be remobilized. Therefore, AMC should be applied to soils that contain plants that are unable to alter the lead phases in the shooting range soil. Efforts should be particularly made to ensure that lead cannot be transformed to the exchangeable phase.
\end{abstract}

\section{Introduction}

In the soil of shooting ranges, lead derived from spent bullets typically accumulates at a very high concentration, causing heavy lead contamination in the soil. Shooting activity has continued in Tajimi shooting range in Gifu, Japan; however, its activity has been prohibited after the detection of heavy lead contamination in the shooting range. A typical method of remediation of toxic-metal-contaminated soil is excavation and transport to landfill sites in Japan. However, shooting ranges have an extensive area and a very low asset value due to their location away from residential areas. Thus, this method could not be applied due to its relatively high cost, which resulted in prohibiting entry into the shooting range.

Chemical immobilization techniques represent a simple and eco-friendly approach for the prevention of toxic metal leaching from contaminated soils. Since the toxic metals are not removed from the soil following immobilization, remaining instead in the soil, better understanding of the immobilization mechanisms, that is, the formation of insoluble phases by the material and the subsequent dissolution of the toxic metals from the material following changes in soil parameters such as soil $\mathrm{pH}$ and oxic-redox conditions, is important to enhance the reliability of immobilization techniques [1].

Animal manure is the most abundant organic waste material and is mainly generated from cattle, swine, and poultry farms in Japan. The quantity of animal manure generated annually is estimated at $8.0 \times 10^{7}$ tons as fresh weight, which corresponded to about $25 \%$ of organic waste material in Japan [2]. Thus, it is necessary to recycle animal manure to reduce the waste material. Animal manure compost (AMC) has been studied to evaluate its potential use as an immobilization material [3-7]. AMC not only has the ability to immobilize 
TABLE 1: Selected physicochemical properties of the soil used in this study (dried weight basis).

\begin{tabular}{lccccccccc}
\hline $\begin{array}{l}\text { Sand } \\
(\%)\end{array}$ & $\begin{array}{c}\text { Silt } \\
(\%)\end{array}$ & $\begin{array}{c}\text { Clay } \\
(\%)\end{array}$ & $\mathrm{pH}$ & $\begin{array}{c}\mathrm{EC} \\
\left(\mathrm{mS} \mathrm{m}^{-1}\right)\end{array}$ & $\begin{array}{c}\mathrm{TC} \\
\left(\mathrm{mgg}^{-1}\right)\end{array}$ & $\begin{array}{c}\mathrm{TN} \\
\left(\mathrm{mgg}^{-1}\right)\end{array}$ & $\begin{array}{c}\text { WSOC } \\
\left(\mathrm{mg} \mathrm{kg}^{-1}\right)\end{array}$ & $\begin{array}{c}\text { Total Pb } \\
\left(\mathrm{mg} \mathrm{kg}^{-1}\right)\end{array}$ & $\begin{array}{c}\text { Amorphous Fe } \\
\left(\mathrm{mgg}^{-1}\right)\end{array}$ \\
\hline 46 & 27 & 27 & 6.9 & 3.4 & 16.1 & 1.3 & 138 & 21 & 3 \\
\hline
\end{tabular}

${ }^{* 1}$ Water-soluble organic carbon.

toxic metals in soils [3-7] but also has advantages that inorganic immobilization materials do not have; that is, AMC contains organic matter and nutrients that can stimulate plant growth and microbial activity in soils that have been affected by metal toxicity [8-11]. Although these advantages may encourage the application of AMC onto contaminated soils, less is known about the mechanisms of immobilization by AMC $[12,13]$ compared with other inorganic and organic waste materials [14], particularly the applicability of AMC to the shooting range soil and the remobilization of lead that was once immobilized by AMC.

Katoh et al. [13, 15, 16] conducted several studies to elucidate the mechanisms of lead immobilization by AMC using the inorganic and organic components of specifically fractionated AMC to understand the suitable chemical properties of AMC to immobilize lead present in the shooting range soil. The studies revealed that the inorganic components in AMC can immobilize lead more effectively than the organic components [13]. A high phosphorus content in the inorganic components of swine manure compost effectively immobilized lead because of the precipitation of lead phosphate minerals that have low solubility products. In addition, maturation of cattle manure makes the organic components more suitable for lead immobilization because of the resulting decrease in water-soluble organic matter, which can enhance lead mobility. On the basis of these results, Katoh et al. [13, 15] suggested that compost that contains an inorganic content with a high phosphorus level, such as swine manure compost, and an organic component that has undergone maturation, such as cattle manure compost, was the most suitable to immobilize lead in soils. In addition, they pointed out that inorganic/organic components ratio of $25: 75$ was suitable to both immobilize lead and restore microbial activity in the shooting range soil [16]. Furthermore, it was demonstrated that such AMC can reduce lead bioavailability in the soil, resulting in a reduction in lead uptake by plants [15]. However, these results do not enhance the reliability of AMC as an immobilization material because lead, once immobilized, might be remobilized by changes in the soil environment [17].

The interface between the soil and the plant is known as the rhizosphere; in this region, root activity greatly influences the soil environment. The physical, chemical, and biological properties of the rhizosphere soil are different from those of the soil that does not contain plants. The plant roots penetrate the soil and exude organic matter such as organic acids, sugars, amino acids, and enzymes, which change the soil $\mathrm{pH}$, redox potential, microbial activities, biomass, organic matter content, and the chemical speciation of elements [18]. Thus, lead immobilized by the inorganic and organic components in AMC has the potential to be remobilized in the rhizosphere soil. For example, the decomposition of organic matter by microorganisms leads to the enhanced release of lead sorbed onto the organic matter [19]. Larger quantities of lead are dissolved from pyromorphite in the presence of an organic acid than in the presence of water, even though pyromorphite is one of the most stable lead minerals [20]. Furthermore, $\mathrm{pH}$ changes influence the sorption/desorption behavior of lead onto inorganic and organic materials in soil [21, 22]. Therefore, if lead immobilized onto AMC is exposed to rhizosphere effects, lead may be remobilized; however, to the best of our knowledge, the degree to which this occurs has not been investigated. There is a need to investigate the rhizosphere effect on lead immobilization to enhance the reliability of immobilization by AMC because the lead once immobilized by AMC is exposed to the rhizosphere effect of native plant in the shooting range soil.

We have investigated the bioavailability, phases, and release characteristics of AMC-sorbed lead in rhizosphere soil in which plants with either high or low tolerance to lead toxicity were grown. We aimed to clarify the magnitude of lead release from lead-immobilized AMC in rhizosphere soil compared with that in bulk soil. On the basis of the results obtained, we discuss lead immobilization techniques using AMC in the shooting range soil.

\section{Materials and Methods}

2.1. Soil Preparation. Brown forest soil with a light clay texture was collected from $5-15 \mathrm{~cm}$ depths from $35^{\circ} 22^{\prime} 13^{\prime \prime} \mathrm{N}$, $137^{\circ} 8^{\prime} 42^{\prime \prime} \mathrm{E}$ in Tajimi, Gifu, Japan, and used as the basic soil for plant cultivation. The sampling site was located near a shooting range but was not contaminated by lead. Before use, the soil $\mathrm{pH}$ was adjusted to 7 using calcium carbonate. This was done to adjust the soil $\mathrm{pH}$ to match that of the compost used, because $\mathrm{pH}$ significantly enhances or reduces lead mobility and bioavailability [23]. The soil was air-dried, passed through a $2 \mathrm{~mm}$ sieve, and kept at room temperature prior to the cultivation tests. Table 1 shows selected chemical properties of the soil. The total lead content of the soil was equal to the background level of $21 \mathrm{mg} \mathrm{kg}^{-1}$ and the final soil pH was 6.9.

\subsection{Fractionation of Inorganic and Organic Components and} Preparation of Lead-Sorbed Simulated Compost. In this study, the compost was prepared by mixing the inorganic fraction of swine manure compost and the acid-insoluble organic fraction of cattle manure compost. We selected these compost fractions since each fraction can immobilize lead more effectively and strongly than other composts [13]. Commercial swine and cattle manure compost (Fujimi Kogyo Co., Japan) were used to obtain the inorganic and acid-insoluble organic 
TABLE 2: Selected chemical properties of the lead-sorbed inorganic and organic compost fractions used in this study (dried weight basis).

\begin{tabular}{lcccccc}
\hline Fraction & $\begin{array}{c}\mathrm{WSOC}^{* 1} \\
\left(\mathrm{mg} \mathrm{kg}^{-1}\right)\end{array}$ & $\begin{array}{c}\mathrm{Pb} \\
\left(\mathrm{mg} \mathrm{g}^{-1}\right)\end{array}$ & $\begin{array}{c}\mathrm{C} \\
\left(\mathrm{mgg}^{-1}\right)\end{array}$ & $\begin{array}{c}\text { Total } \\
\left(\mathrm{mgg} \mathrm{g}^{-1}\right)\end{array}$ & $\begin{array}{c}\mathrm{Ca} \\
\left(\mathrm{mgg}^{-1}\right)\end{array}$ & $\begin{array}{c}\mathrm{P} \\
\left(\mathrm{mgg}^{-1}\right)\end{array}$ \\
\hline Inorganic fraction & $\mathrm{ND}^{* 2}$ & 171 & $\mathrm{ND}$ & $\mathrm{ND}$ & 114 & 92.9 \\
Organic fraction & 1330 & 27.2 & 447 & 18.2 & 0.2 \\
\hline
\end{tabular}

${ }^{* 1}$ Water-soluble organic carbon.

${ }^{* 2}$ Not determined.

fractions, respectively. The organic matter contents and $\mathrm{pH}$ in swine and cattle manure compost were 747 and $850 \mathrm{mg} \mathrm{g}^{-1}$ and 8.0 and 6.9, respectively, and other chemical properties of compost have been reported previously [13]. Compost fractionation followed the method described by Katoh et al. [13]. Briefly, commercial swine manure compost was combusted at $600^{\circ} \mathrm{C}$ for $2 \mathrm{~h}$. The residue after combustion was collected and used as the inorganic compost fraction. Commercial cattle manure compost was subjected to extraction with $1 \mathrm{M}$ $\mathrm{HCl}(1: 50 \mathrm{solid} /$ liquid ratio) for $1 \mathrm{~h}$ to remove almost all the inorganic and acid-soluble organic fractions in the compost [24]. The residue after extraction was collected and used as the organic compost fraction.

After the fractionation, lead was sorbed on each fraction. The inorganic and organic fractions were added into polypropylene (PP) tubes containing 2 and $20 \mathrm{~g}-\mathrm{Pb} / \mathrm{L}$, respectively, as $\mathrm{Pb}\left(\mathrm{NO}_{3}\right)_{2}$ in $5 \mathrm{mM} \mathrm{KNO}_{3}(\mathrm{pH}$ ) at a $1: 50$ solid/liquid ratio. The fractions were then shaken for $24 \mathrm{~h}$ and $\mathrm{pH}$ was adjusted to 5 . After centrifugation $(5000 \mathrm{rpm}$, $5 \mathrm{~min}$ ), the deposit was collected and washed five times with ultrapure water, and $\mathrm{pH}$ was adjusted to 7 using $0.001-0.1 \mathrm{M}$ $\mathrm{KOH}$, and the deposit was air-dried and passed through a $0.5 \mathrm{~mm}$ sieve. Table 2 shows selected chemical properties of the lead-sorbed fractions. The lead-sorbed inorganic and organic fractions were mixed at a ratio of $1: 3$, and the mixed sample was used as the lead-sorbed compost. The mixing ratio of the inorganic and organic fractions was a suitable ratio for lead immobilization [16] and was within the average values for Japanese AMC [25].

2.3. Plant Growth Test. A plant growth test was carried out in $15 \mathrm{~mL}$ PP tubes. The tube bottom was cut, and cotton was placed inside the bottom. The lead-sorbed compost was mixed well with the soil to give a final lead concentration of $1000 \mathrm{mg}-\mathrm{Pb} \mathrm{kg}^{-1}$, which corresponded to the ratio of $15.8 \mathrm{~g}$ of the lead-sorbed compost to one $\mathrm{kg}$ of soil. Into each tube was placed $12.5 \mathrm{~g}$ of soil, and seeds of buckwheat (Fagopyrum esculentum) or Guinea grass (Panicum maximum J.) were sown. Tubes without plants were also prepared as controls. In addition, plants were also grown in soil that did not contain the lead-sorbed compost. Three tubes were prepared for each treatment. After germination, the plants were thinned, and one plant per tube was grown for 3 months at $25^{\circ} \mathrm{C}$ (room temperature) with a $14 \mathrm{~h}$ photoperiod using a $40 \mathrm{~W}$ horticultural lamp. Ultrapure water containing $10 \mathrm{mg} / \mathrm{L} \mathrm{KNO}_{3}$ was irrigated from the bottom of the tube for $30 \mathrm{~min}$ to $1 \mathrm{~h}$ once every two days. After plant growth was complete, the aboveground plant was cut, the plant height was measured, and then the shoot was dried and weighed. The total concentration of lead in the dried shoots was determined. The soil sample was collected from the tube. This study defined the entire soil sample collected from each tube as rhizosphere soil because the inside of the tubes was fully covered with plant roots. The collected soil samples were air-dried and passed through a 2 or $0.425 \mathrm{~mm}$ sieve before chemical analysis and lead release tests.

2.4. Lead Release Tests for Rhizosphere Soil. Following the period of plant growth, the kinetics of lead release from the rhizosphere soil containing lead-sorbed compost were investigated following the method described by Zhang and Ryan [26]. Briefly, a $1.0 \mathrm{~g}$ sample of the AMC-containing soil in which plants had been either grown or not grown was added to a beaker containing $1 \mathrm{~L}$ of $0.1 \mathrm{M} \mathrm{NaNO}_{3}$ at $\mathrm{pH} 3,4,5,6$, or 7 . The soil samples that had been passed through a $0.425 \mathrm{~mm}$ sieve were used. After the addition of the soil, stirring was started, while the $\mathrm{pH}$ of the sample was adjusted to \pm 0.2 of the target $\mathrm{pH}$ using $0.01 \mathrm{M} \mathrm{NaOH}$ or $\mathrm{HNO}_{3}$. A $10 \mathrm{~mL}$ aliquot of the suspension was sampled at intervals of $1-90 \mathrm{~min}$, passed through a $0.45 \mu \mathrm{m}$ filter, and analyzed to determine the lead concentration using an inductively coupled plasma-atomic emission spectrometer (ICP-AES; ULTIMA2; HORIBA Ltd., Japan).

2.5. Analytical Methods. The $\mathrm{pH}$ and electrical conductivity (EC) of the soil samples were measured in ultrapure water with a solid/liquid ratio of $1: 10$ using a $\mathrm{pH}$ meter (MM60R; DKK-TOA Co., Japan). The soil texture was determined using the hydrometer method [27]. The total carbon and total nitrogen (TC and TN, resp.) contents of the soil and compost fraction samples were determined using a carbon, hydrogen, and nitrogen (CHN) elemental analyzer (MT-6; Yanaco New Science Inc., Japan). Water-soluble organic carbon (WSOC) was extracted from the air-dried soil and compost fraction samples using ultrapure water at a solid/liquid ratio of 1:10 and analyzed using a total organic carbon (TOC) analyzer (TOC-VWS; Shimadzu Co., Japan). $\mathrm{CaCl}_{2}$-soluble lead was extracted from the air-dried soil using $0.1 \mathrm{M} \mathrm{CaCl}_{2}$ at a solid/liquid ratio of $1: 10$ and was analyzed using ICP-AES. Amorphous iron was extracted using Shuman's method [28]. The total elemental contents in the soil, plant shoot, and compost fraction samples were determined by acid digestion with $\mathrm{HNO}_{3}$ and $\mathrm{HCl}$ using a microwave. A sequential extraction procedure was performed on the air-dried soil sample $(0.425 \mathrm{~mm})$ according to the procedure described by Tessier 
TABLE 3: Shoot biomass of plant.

\begin{tabular}{|c|c|c|c|c|}
\hline Plant & Treatment & $\begin{array}{l}\text { Height } \\
(\mathrm{cm})\end{array}$ & $\begin{array}{l}\text { Dry weight } \\
\left(\mathrm{mg} \mathrm{plant}^{-1}\right)\end{array}$ & $\begin{array}{c}\mathrm{Pb} \text { concentration } \\
\left(\mu \mathrm{g} \mathrm{g}^{-1}\right)\end{array}$ \\
\hline \multirow{2}{*}{ Buckwheat } & Control & $81.5 \pm 6.6$ & $268 \pm 57$ & $\mathrm{ND}^{* 1}$ \\
\hline & $+\mathrm{Pb} /$ compost & $80.4 \pm 1.6$ & $355 \pm 55$ & $891 \pm 274$ \\
\hline$P$ value & & 0.873 & 0.335 & \\
\hline \multirow{2}{*}{ Guinea grass } & Control & $36.2 \pm 6.4$ & $72 \pm 25$ & ND \\
\hline & $+\mathrm{Pb} /$ compost & $11.5 \pm 2.5$ & $7 \pm 2$ & $151 \pm 22$ \\
\hline$P$ value & & $0.023^{*}$ & 0.064 & \\
\hline
\end{tabular}

${ }^{* 1}$ Not detected $\left(<0.5 \mu \mathrm{gg}^{-1}\right)$.

et al. [29]. In short, each fraction was extracted with $1 \mathrm{M}$ $\mathrm{MgCl}_{2}$ solution (exchangeable fraction), $1 \mathrm{M}$ sodium acetate solution at $\mathrm{pH} 5$ (carbonate fraction), $0.04 \mathrm{M} \mathrm{NH}_{2} \mathrm{OH}-\mathrm{HCl}$ in $25 \%(\mathrm{v} / \mathrm{v}) \mathrm{HOAc}$ in a $95^{\circ} \mathrm{C}$ water bath with occasional agitation (Fe/Mn oxide fraction), $0.02 \mathrm{M} \mathrm{HNO}_{3}$ and $5 \mathrm{~mL}$ $30 \% \mathrm{H}_{2} \mathrm{O}_{2}$ solution in $85^{\circ} \mathrm{C}$ water bath with occasional agitation (organic fraction), and $5 \mathrm{~mL} \mathrm{HNO}_{3}$ and $2 \mathrm{~mL} \mathrm{HCl}$ using a microwave oven (residual fraction). All the extracted and digested solutions were passed through a $0.45 \mu \mathrm{m}$ filter and analyzed using ICP-AES to determine the elemental concentrations.

2.6. Statistical Analysis. Statistical analyses were performed using JMP Ver. 8.0.2 (SAS Institute Inc., USA). Analysis of variance (ANOVA) was conducted to compare the height and dry weight of plant shoots, soil $\mathrm{pH}$, WSOC, and $\mathrm{CaCl}_{2}$ soluble lead in the soil, as well as the percentage of lead dissolved in the dissolution test. The differences between the mean values were determined using Tukey's honestly significant difference (HSD) test at a 95\% confidence level.

\section{Results and Discussion}

3.1. Plant Shoot Biomass. Table 3 shows the shoot biomass and lead concentration for plants grown in the rhizosphere soil with or without the lead-immobilized compost. The shoot height and dry weight of buckwheat grown in the presence of lead-immobilized compost did not significantly differ from those grown without the compost. However, the lead concentration in buckwheat grown in the presence of lead-immobilized compost was relatively high at $891 \mu^{g^{-1}}$. Buckwheat is known to tolerate high levels of lead and to act as a lead hyperaccumulator, which is defined as a plant containing over $1000 \mathrm{ug} \mathrm{g}^{-1}$ of lead in its shoots [30]. Therefore, in the rhizosphere soil containing lead-immobilized compost, plant growth was not suppressed by lead toxicity, despite the fact that lead was absorbed by the buckwheat root. In contrast, the presence of lead-immobilized compost led to growth suppression in Guinea grass, as this species is known to exhibit lower lead tolerance [31].

In both plant types, lead was absorbed from the rhizosphere soil, even though the lead in the soil was immobilized and insoluble, suggesting that rhizosphere effects had altered the immobilized lead to increase bioavailability. In the bulk lead-contaminated soil amended with the AMC, lead uptake
TABLE 4: Rhizosphere soil pH for buckwheat, Guinea grass, and bulk soil (no plant).

\begin{tabular}{|c|c|c|}
\hline Plant & Treatment & Soil pH \\
\hline \multirow{2}{*}{ Buckwheat } & $\mathrm{No} \mathrm{Pb}$ & $5.6 \pm 0.0^{\mathrm{C} * 1}$ \\
\hline & $\mathrm{Pb}$-compost & $6.1 \pm 0.0^{\mathrm{B}}$ \\
\hline \multirow{2}{*}{ Guinea grass } & $\mathrm{No} \mathrm{Pb}$ & $6.9 \pm 0.0^{\mathrm{A}}$ \\
\hline & $\mathrm{Pb}$-compost & $6.8 \pm 0.0^{\mathrm{A}}$ \\
\hline \multicolumn{2}{|c|}{ No plant } & $6.8 \pm 0.0^{A}$ \\
\hline
\end{tabular}

${ }^{* 1}$ Different letters indicate significant differences at $P<0.05$ on the basis of Tukey's HSD test.

is suppressed at the same level as the inorganic immobilization material [15]. According to Katoh et al. [32], in the rhizosphere soil amended with hydroxyapatite, which is the main component of the inorganic compost fraction used in this study [13], lead was not absorbed by the plant root. This is because lead is immobilized by hydroxyapatite, mainly precipitating as pyromorphite, which has a low solubility product $\left(\log K_{\mathrm{sp}}=-25.05\right.$ [14]). In addition, in this study, the lead concentration in buckwheat $\left(891 \mu \mathrm{g} \mathrm{g}^{-1}\right)$ was lower than that previously reported $\left(4200 \mu \mathrm{gg}^{-1}\right.$ [30]), which suggests that a large part of the lead immobilized by the inorganic compost component was not altered by rhizosphere effects to be bioavailable. Therefore, lead uptake by both plants would be best explained by partial lead release from the leadimmobilized organic fraction in the compost. The lead release from the lead-immobilized organic fraction in the compost is discussed in detail in the later section relating to the lead phases in the soil.

3.2. Soil pH, Water-Soluble Organic Carbon (WSOC), $\mathrm{CaCl}_{2}$ Soluble Lead, and Lead Phases. The $\mathrm{pH}$ of the buckwheat rhizosphere soil with and without the lead-immobilized compost was 5.6 and 6.1, respectively, which was significantly lower than that of the Guinea grass rhizosphere soil and the nonplanted soil (Table 4), indicating that the rhizosphere effect of buckwheat caused the $\mathrm{pH}$ reduction.

The level of WSOC in the rhizosphere soil of buckwheat was significantly higher than that in the nonplanted soil (Figure 1(a)), while the level of WSOC in the rhizosphere soil of Guinea grass was higher but not significantly different from that in the nonplanted soil. The higher level of WSOC in the buckwheat rhizosphere soil would be attributed to 




(a)



(b)

FIGURE 1: (a) Water-soluble organic carbon (WSOC) and (b) $\mathrm{CaCl}_{2}$-soluble lead in the rhizosphere soil of buckwheat (BW) and Guinea grass (GG) and bulk soil (no plant) containing lead-sorbed compost. Bars indicate the standard error (SE) $(n=3)$. Different letters indicate significant differences at $P<0.05$ based on Tukey's HSD test.

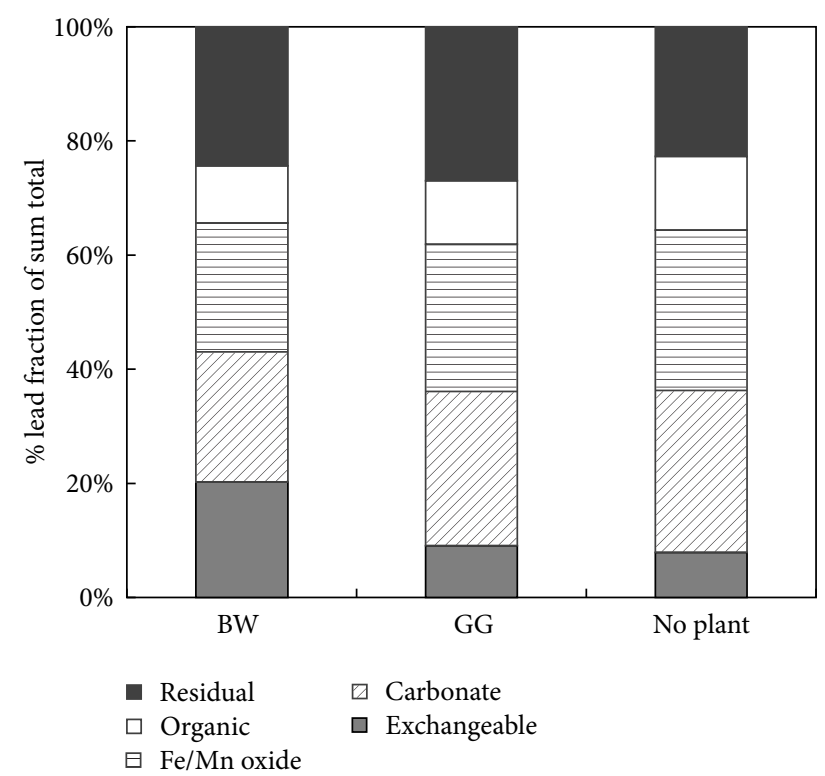

Figure 2: Sequential extraction of lead from the rhizosphere soil of buckwheat (BW) and Guinea grass (GG) and bulk soil (no plant) containing lead-sorbed compost.

both the release of water-soluble organic matter from the root and decomposition of the organic fraction of the compost. The amount of $\mathrm{CaCl}_{2}$-soluble lead in the rhizosphere soil of buckwheat was significantly higher than that present in the rhizosphere soil of Guinea grass and nonplanted soil (Figure 1(b)). The amount of $\mathrm{CaCl}_{2}$-soluble lead in the rhizosphere soil of Guinea grass was slightly higher than that in the nonplanted soil but was not significantly different.

Figure 2 shows the lead fractions recorded in sequential extractions. The average recovery, which is defined in this study as the ratio of the sum total level of each fraction
(Figure 2) to the total level of lead in the soil $\left(1000 \mathrm{mg} \mathrm{kg}^{-1}\right)$, was $93 \pm 6 \%$. The ratio of each fraction in the nonplanted soil containing the lead-sorbed compost was $8 \%$ for the exchangeable fraction, $28 \%$ for the carbonate fraction, $28 \%$ for the $\mathrm{Fe} / \mathrm{Mn}$ oxide fraction, $13 \%$ for the organic fraction, and $23 \%$ for the residual fraction, demonstrating that $36 \%$ of lead in the soil (exchangeable and carbonate fractions) was present in relatively soluble states. According to other studies $[15,16]$, wherein the lead distribution by sequential extraction was investigated using the lead-contaminated soil amended with the AMC, the residual and exchangeable fractions ranged from $17 \%$ to $49 \%$ and from $0 \%$ to $1 \%$, respectively. The residual and exchangeable lead fractions in this study were compatible with those previously reported, although the leadimmobilized compost was applied to the noncontaminated soil in this study. In addition, the application of organic waste material to the contaminated soil alters the lead phases to more insoluble state $[33,34]$. The distribution of each fraction, particularly the exchangeable and carbonate fractions, in the rhizosphere soil of Guinea grass was almost the same as that in the nonplanted soil, suggesting that the growth of Guinea grass did not influence the lead phases in the rhizosphere soil containing the lead-immobilized compost. In contrast, the exchangeable fraction made up $20 \%$ of the lead in the rhizosphere soil of buckwheat, while the ratios of carbonate and $\mathrm{Fe} / \mathrm{Mn}$ oxide fractions decreased as compared with the nonplanted soil. These results indicate that the growth of buckwheat caused an increase in the amount of exchangeable lead in the rhizosphere soil containing leadsorbed compost.

The chemical and biological properties of the rhizosphere soil differ considerably from those of the nonplanted soil because of root exudation, which changes the redox potential, microbial activities, biomass, and the chemical speciation of elements [18]. In the rhizosphere soil of buckwheat, the $\mathrm{pH}$ 


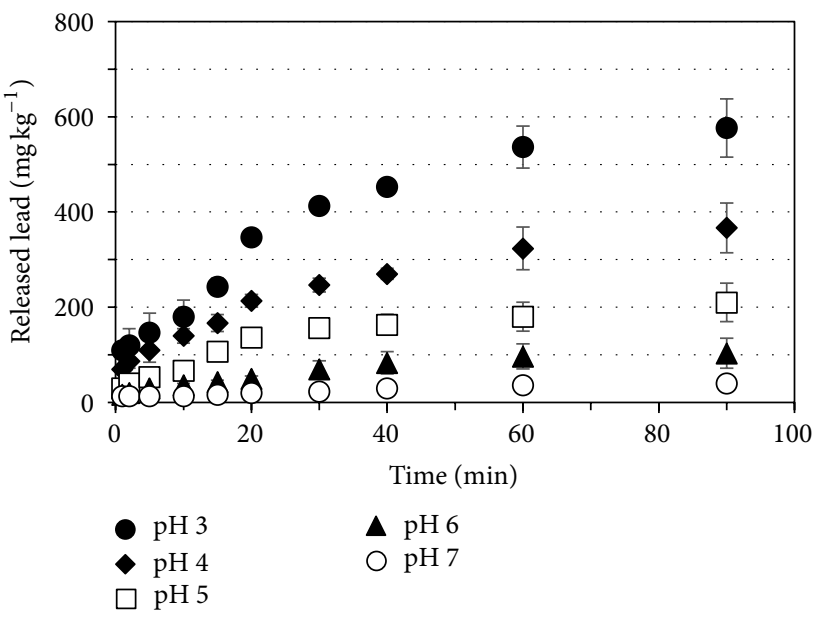

(a) Buckwheat

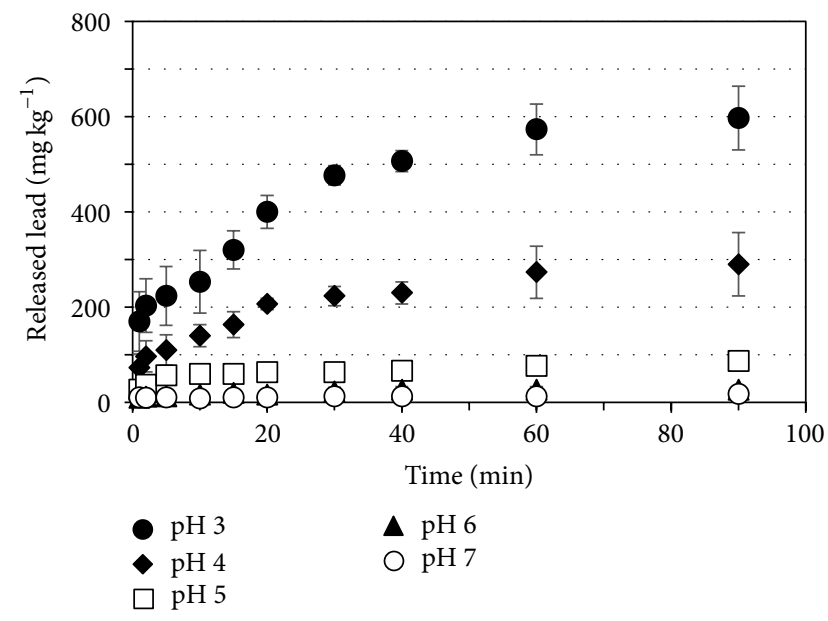

(b) Guinea grass



(c) No plant

FIGURE 3: Lead release from rhizosphere soil of buckwheat and Guinea grass and bulk soil (no plant) with lead-sorbed compost. Bars indicate the SE $(n=3)$.

decreased compared with that of the nonplanted soil. In addition, the level of WSOC in the rhizosphere soil of buckwheat was significantly higher than that in the nonplanted soil. Therefore, such changes in the rhizosphere soil of buckwheat would induce the lead immobilized on the compost to become more soluble; the ratio of the exchangeable fraction increased, resulting in the observed enhancement in the level of $\mathrm{CaCl}_{2}$-soluble lead. As discussed in the previous section, lead immobilized by the inorganic fraction of the compost is relatively stable with regard to chemical and biological changes in the soil. Thus, lead immobilized by the organic fraction in the compost would be responsible for the increase in the exchangeable fraction in the sequential extractions and the level of $\mathrm{CaCl}_{2}$-soluble lead. Lead is sorbed onto organic matter by complexation with surface functional groups such as carboxyl groups [12]; a pH decrease then causes lead sorbed onto the organic matter to be released $[12,35]$. In addition, lead-sorbed organic matter is redistributed by the decomposition of the organic matter to which the lead is sorbed [19]. Therefore, in the rhizosphere soil of buckwheat, the high rhizosphere effect might induce a $\mathrm{pH}$ decrease and an enhancement in the microbial decomposition of organic matter as a result of the high level of water-soluble organic matter, causing the lead to be released from the organic fraction in the compost. In contrast, in the rhizosphere soil of Guinea grass, the relatively low rhizosphere effect would explain the absence of a significant enhancement in the level of $\mathrm{CaCl}_{2}$-soluble lead and the lack of change in the distribution of each fraction in the sequential extractions.

3.3. Lead Release from Rhizosphere Soil. Figure 3 shows the lead released from the rhizosphere soil of buckwheat and Guinea grass and nonplanted soil containing leadimmobilized compost as a function of contact time. The amount of lead released increased with an increase in time for all the soils and solution pHs. In addition, for the same soil, a decrease in the solution $\mathrm{pH}$ resulted in an increase in the amount of lead released. With the exception of $\mathrm{pH} 3$, it may be seen that the amount of lead released at a specific $\mathrm{pH}$ followed the order rhizosphere soil of buckwheat $>$ rhizosphere soil of Guinea grass $=$ nonplanted soil. Table 5 shows the percentage 
TABLE 5: Lead released after $90 \mathrm{~min}$ as a percentage of the total lead content in soil.

\begin{tabular}{lccccc}
\hline \multirow{2}{*}{ Plant } & \multicolumn{5}{c}{ Solution pH } \\
& 3 & 4 & 5 & 6 & 7 \\
\hline Buckwheat & $58 \pm 6$ & $37 \pm 5$ & $21 \pm 4^{\mathrm{A} * 1}$ & $10 \pm 3^{\mathrm{A}}$ & $4 \pm 1^{\mathrm{A}}$ \\
Guinea grass & $60 \pm 7$ & $29 \pm 7$ & $9 \pm 0^{\mathrm{B}}$ & $3 \pm 1^{\mathrm{AB}}$ & $2 \pm 0^{\mathrm{B}}$ \\
No plant & $59 \pm 8$ & $22 \pm 3$ & $5 \pm 0^{\mathrm{B}}$ & $2 \pm 0^{\mathrm{B}}$ & $1 \pm 0^{\mathrm{B}}$ \\
\hline
\end{tabular}

${ }^{* 1}$ Different letters in the same column indicate significant differences at $P<$ 0.05 on the basis of Tukey's HSD test.

of lead released at $90 \mathrm{~min}$ as a percentage of the total lead

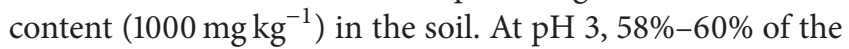
lead in the soil was released, and no significant differences between the soils were observed. In the rhizosphere soil of Guinea grass and nonplanted soil, the percentages of lead released decreased with an increase in the solution $\mathrm{pH}$, and the values were not significantly different between the two soils. Similarly, in the rhizosphere soil of buckwheat, the percentages of lead released decreased with an increase in the solution $\mathrm{pH}$, but they were significantly higher than those in the rhizosphere soil of Guinea grass and nonplanted soil when the solution $\mathrm{pH}$ was between 5 and 7. To assess the release rates and initial release rates, the kinetics data were analyzed according to the pseudo-second-order rate equation given as follows:

$$
\frac{t}{q_{t}}=\frac{1}{k_{2} q_{e}^{2}}+\frac{1}{q_{e}} t
$$

where $k_{2}$ is the pseudo-second-order rate constant $(\mathrm{kg}$ $\left.(\operatorname{mg~min})^{-1}\right), q_{e}$ and $q_{t}$ are the amounts of lead released $\left(\mathrm{mg} \mathrm{kg}^{-1}\right)$ at equilibrium and at time $t$, respectively, and $t$ is contact time ( $\mathrm{min}$ ). The following expression denotes the initial release rate $\left(\mathrm{mg}(\mathrm{kg} \mathrm{min})^{-1}\right)$ :

$$
h=k_{2} q_{e}^{2} .
$$

The results obtained from the analyses are shown in Table 6 . The data were fitted well by the pseudo-second-order kinetics model with a high determination coefficient, and the amounts of lead released at equilibrium were estimated, which increased with a decrease in the solution $\mathrm{pH}$ within the same soil. Similarly, the initial release rates were assessed. Similarly, the initial release rate increased with a decrease in the solution $\mathrm{pH}$ within the same soil.

At $\mathrm{pH}$ 5-7, higher levels of compost-immobilized lead were released into the rhizosphere soil of buckwheat than in nonplanted soil; there was no significant difference between the lead levels found in the rhizosphere soil of Guinea grass and nonplanted soil. These results were consistent with the results of the lead bioavailability screening and the phase analysis described in Section 3.2. According to the results of the sequential extractions (Figure 2), the exchangeable, carbonate, and $\mathrm{Fe} / \mathrm{Mn}$ oxide fractions in the rhizosphere soil of buckwheat and Guinea grass and nonplanted soil represented $66 \%, 62 \%$, and $64 \%$, respectively, of the sum total of lead recovered, which corresponded to the percentage of lead released after $90 \mathrm{~min}$ at $\mathrm{pH} 3$ (Table 5). Similarly, the sum percentages of exchangeable and carbonate fractions were $43 \%, 36 \%$, and $36 \%$, respectively; these values were larger than the percentages of lead released at $\mathrm{pH} 4$. These results suggest that lead immobilized by the compost was released from the exchangeable, carbonate, and Fe/Mn oxide fractions at $\mathrm{pH} 3$ and from the exchangeable fraction and a part of carbonate fraction at $\mathrm{pH}$ 4. Thus, small differences in the distribution of the exchangeable to $\mathrm{Fe} / \mathrm{Mn}$ oxide fractions would explain the absence of significant differences in the amount of lead released for each soil type at both $\mathrm{pH} 3$ and $\mathrm{pH}$ 4. The exchangeable fraction in the rhizosphere soil of buckwheat and Guinea grass and nonplanted soil represented $20 \%, 9 \%$, and $8 \%$, respectively, of the total lead recovered, and these values were almost equal to the percentage of lead released in the lead release test at $\mathrm{pH} 5$. This suggests that the lead that was released was derived from the exchangeable fraction in the rhizosphere soils and nonplanted soil at $\mathrm{pH}$ 5-7. Therefore, the differences between the percentage of exchangeable lead present in the rhizosphere soil of buckwheat and other soils would be responsible for the significant differences in the amount of lead released in the lead release test at $\mathrm{pH} 5-7$. These results suggest that the rhizosphere effect induces an increase in the percentage of lead present in the exchangeable phase and leads to the remobilization of AMC-sorbed lead. Therefore, AMC should be applied to soils that contain plants that are unable to alter the lead phases present in the shooting range soil. In particular, efforts should be made to ensure that lead cannot be transformed to the exchangeable phase when AMC is used as an immobilization material in the shooting range soil. However, lead uptake and suppression of plant growth was observed in Guinea grass, despite the fact that lead was not remobilized in the rhizosphere soil. This observation would imply that even miniscule changes in lead bioavailability resulting from a weak rhizosphere effect could be enough to cause an increase in lead uptake by plants. Therefore, it should also be noted that even plants with a low potential to remobilize lead may take up lead immobilized by AMC, even though that lead is not released from the rhizosphere soil to the nonrhizosphere soil.

\section{Conclusions}

The shoot height and dry weight of buckwheat grown in rhizosphere soil of shooting range with lead-immobilized compost did not significantly differ from that grown without compost, while the presence of lead suppressed the growth of Guinea grass. In both plant types, lead was absorbed from the rhizosphere soil although the lead had been immobilized by the compost. The presence of buckwheat in the rhizosphere soil caused a reduction in the rhizosphere soil $\mathrm{pH}$ and an increase in the level of WSOC compared with that in nonplanted soil. In addition, the presence of buckwheat altered the lead phases present; the relative amount of the soluble exchangeable fraction increased, resulting in an increase in the $\mathrm{CaCl}_{2}$-soluble lead level. In contrast, the presence of Guinea grass did not significantly change the lead bioavailability or the phases present. 
TABLE 6: Computed values of the pseudo-second-order rate constant $\left(k_{2}\right)$ and initial lead dissolution rate $(h)$.

\begin{tabular}{|c|c|c|c|c|c|}
\hline Plant & $\mathrm{pH}$ & $\begin{array}{c}q_{\mathrm{eq}} \\
\left(\mathrm{mg} \mathrm{kg}^{-1}\right)\end{array}$ & $\begin{array}{c}k_{2} \\
\left(\mathrm{~kg}(\mathrm{mg} \mathrm{min})^{-1}\right)\left(\times 10^{-4}\right)\end{array}$ & $R^{2}$ & $\begin{array}{c}h \\
\left(\operatorname{mg}(\mathrm{kg} \mathrm{min})^{-1}\right)\end{array}$ \\
\hline \multirow{5}{*}{ Buckwheat } & 3 & 670 & 0.870 & 0.948 & 39 \\
\hline & 4 & 402 & 1.72 & 0.962 & 28 \\
\hline & 5 & 236 & 2.73 & 0.968 & 15 \\
\hline & 6 & 120 & 4.70 & 0.944 & 7 \\
\hline & 7 & 44 & 14.2 & 0.913 & 3 \\
\hline \multirow{5}{*}{ Guinea grass } & 3 & 651 & 1.55 & 0.979 & 66 \\
\hline & 4 & 309 & 3.53 & 0.984 & 34 \\
\hline & 5 & 86 & 21.0 & 0.982 & 16 \\
\hline & 6 & 28 & 61.0 & 0.986 & 5 \\
\hline & 7 & 17 & 79.9 & 0.944 & 2 \\
\hline \multirow{5}{*}{ No plant } & 3 & 643 & 1.53 & 0.979 & 64 \\
\hline & 4 & 244 & 8.47 & 0.982 & 50 \\
\hline & 5 & 54 & 74.1 & 0.998 & 21 \\
\hline & 6 & 17 & 42.7 & 0.847 & 1 \\
\hline & 7 & 11 & 149 & 0.934 & 2 \\
\hline
\end{tabular}

The lead release test in solution using the rhizosphere soil showed that lead immobilized by the compost was released more easily from the soil at low solution $\mathrm{pH}$, regardless of the soil types. Between solution $\mathrm{pH} 5$ and solution $\mathrm{pH} 7$, the amount of lead released from the compost was higher in the rhizosphere soil of buckwheat than in the nonplanted soil, whereas there was no significant difference between the rhizosphere soil of Guinea grass and nonplanted soil. The lead released from the rhizosphere soil between solution $\mathrm{pH} 5$ and solution pH 7 would be derived from the exchangeable lead form. These results suggest that the increase in the quantity of exchangeable lead resulting from the rhizosphere effect induces lead immobilized by the AMC to be remobilized. Therefore, AMC should be applied to soils that contain plants that are unable to alter the lead phases present in the shooting range soil. In particular, efforts should be made to ensure that lead cannot be transformed to the exchangeable phase. However, it should be also noted that even plants with a low potential to remobilize lead may take up lead immobilized by AMC from the rhizosphere soil of shooting range.

\section{Competing Interests}

The authors declare that there are no competing interests regarding the publication of this paper.

\section{Acknowledgments}

This study was supported by the Japan Society for the Promotion of Science (JSPS) KAKENHI [Grant no. 23710089]. The ICP-AES and CHN elemental analyzer used for chemical analyses in this study was made available by the Division of Instrumental Analysis at Gifu University. The authors are grateful to Professor F. Li and Professor T. Yamada (Gifu University) for allowing the use of the TOC analyzer.

\section{References}

[1] N. Bolan, A. Kunhikrishnan, R. Thangarajan et al., "Remediation of heavy metal(loid)s contaminated soils-to mobilize or to immobilize?" Journal of Hazardous Materials, vol. 266, pp. 141-166, 2014.

[2] Ministry of Agriculture, Forestry and Fisheries (MAFF), Status of Emission and Management of Livestock Manure, 2016, http:// www.maff.go.jp/j/chikusan/kankyo/taisaku/t_mondai/02_kanri/index.html.

[3] R. P. Narwal and B. R. Singh, "Effect of organic materials on partitioning, extractability and plant uptake of metals in an alum shale soil," Water, Air, and Soil Pollution, vol. 103, no. 14, pp. 405-421, 1998.

[4] L. Liu, H. Chen, P. Cai, W. Liang, and Q. Huang, "Immobilization and phytotoxicity of Cd in contaminated soil amended with chicken manure compost," Journal of Hazardous Materials, vol. 163 , no. 2-3, pp. 563-567, 2009.

[5] M. Farrell and D. L. Jones, "Use of composts in the remediation of heavy metal contaminated soil," Journal of Hazardous Materials, vol. 175, no. 1-3, pp. 575-582, 2010.

[6] E. Doelsch, A. Masion, G. Moussard, C. Chevassus-Rosset, and O. Wojciechowicz, "Impact of pig slurry and green waste compost application on heavy metal exchangeable fractions in tropical soils," Geoderma, vol. 155, no. 3-4, pp. 390-400, 2010.

[7] A. Baghaie, A. H. Khoshgoftarmanesh, M. Afyuni, and R. Schulin, "The role of organic and inorganic fractions of cow manure and biosolids on lead sorption," Soil Science and Plant Nutrition, vol. 57, no. 1, pp. 11-18, 2011.

[8] D. J. Walker, R. Clemente, A. Roig, and M. P. Bernal, “The effects of soil amendments on heavy metal bioavailability in two contaminated Mediterranean soils," Environmental Pollution, vol. 122, no. 2, pp. 303-312, 2003.

[9] R. Clemente, Á. Escolar, and M. P. Bernal, "Heavy metals fractionation and organic matter mineralisation in contaminated calcareous soil amended with organic materials," Bioresource Technology, vol. 97, no. 15, pp. 1894-1901, 2006. 
[10] A. Sato, H. Takeda, W. Oyanagi, E. Nishihara, and M. Murakami, "Reduction of cadmium uptake in spinach (Spinacia oleracea L.) by soil amendment with animal waste compost," Journal of Hazardous Materials, vol. 181, no. 1-3, pp. 298-304, 2010.

[11] H.-S. Chen, Q.-Y. Huang, L.-N. Liu, P. Cai, W. Liang, and M. $\mathrm{Li}$, "Poultry manure compost alleviates the phytotoxicity of soil cadmium: influence on growth of pakchoi (Brassica chinensis L.)," Pedosphere, vol. 20, no. 1, pp. 63-70, 2010.

[12] G. Guo, Q. Zhou, and L. Q. Ma, "Availability and assessment of fixing additives for the in situ remediation of heavy metal contaminated soils: a review," Environmental Monitoring and Assessment, vol. 116, no. 1-3, pp. 513-528, 2006.

[13] M. Katoh, W. Kitahara, and T. Sato, "Sorption of lead in animal manure compost: contributions of inorganic and organic fractions," Water, Air, and Soil Pollution, vol. 225, no. 1, article 1828, 2014.

[14] P. Miretzky and A. Fernandez-Cirelli, "Phosphates for Pb immobilization in soils: a review," Environmental Chemistry Letters, vol. 6, no. 3, pp. 121-133, 2008.

[15] M. Katoh, W. Kitahara, R. Yagi, and T. Sato, "Suitable chemical properties of animal manure compost to facilitate $\mathrm{Pb}$ immobilization in soil," Soil and Sediment Contamination, vol. 23, no. 5, pp. 523-539, 2014.

[16] M. Katoh, W. Kitahara, and T. Sato, "Role of inorganic and organic fractions in animal manure compost in lead immobilization and microbial activity in soil," Applied and Environmental Soil Science, vol. 2016, Article ID 7872947, 9 pages, 2016.

[17] P. Sanderson, R. Naidu, and N. Bolan, "The effect of environmental conditions and soil physicochemistry on phosphate stabilisation of $\mathrm{Pb}$ in shooting range soils," Journal of Environmental Management, vol. 170, pp. 123-130, 2016.

[18] D. L. Jones, P. G. Dennis, A. G. Owen, and P. A. W. Van Hees, "Organic acid behavior in soils-misconceptions and knowledge gaps," Plant and Soil, vol. 248, no. 1-2, pp. 31-41, 2003.

[19] A. W. Schroth, B. C. Bostick, J. M. Kaste, and A. J. Friedland, "Lead sequestration and species redistribution during soil organic matter decomposition," Environmental Science and Technology, vol. 42, no. 10, pp. 3627-3633, 2008.

[20] F. Debela, J. M. Arocena, R. W. Thring, and T. Whitcombe, "Organic acid-induced release of lead from pyromorphite and its relevance to reclamation of $\mathrm{Pb}$-contaminated soils," Chemosphere, vol. 80, no. 4, pp. 450-456, 2010.

[21] D. G. Strawn and D. L. Sparks, "Effects of soil organic matter on the kinetics and mechanisms of $\mathrm{Pb}$ (II) sorption and desorption in soil," Soil Science Society of America Journal, vol. 64, no. 1, pp. 144-156, 2000.

[22] X. Guo, S. Zhang, X.-Q. Shan et al., "Characterization of Pb, $\mathrm{Cu}$, and $\mathrm{Cd}$ adsorption on particulate organic matter in soil," Environmental Toxicology and Chemistry, vol. 25, no. 9, pp. 2366-2373, 2006.

[23] P. Schwab, D. Zhu, and M. K. Banks, "Heavy metal leaching from mine tailings as affected by organic amendments," Bioresource Technology, vol. 98, no. 15, pp. 2935-2941, 2007.

[24] E. Frossard, P. Tekely, and J. Y. Grimal, "Characterization of phosphate species in urban sewage sludges by high-resolution solid-state ${ }^{31}$ P NMR," European Journal of Soil Science, vol. 45, no. 4, pp. 403-408, 1994.

[25] T. Yamaguchi, Y. Harada, and M. Tsuiki, "Basic data of animal waste composts," Miscellaneous Publication of the National Agricultural Research Center, vol. 41, pp. 1-178, 2000 (Japanese).
[26] P. Zhang and J. A. Ryan, "Formation of pyromorphite in anglesite-hydroxyapatite suspensions under varying $\mathrm{pH}$ conditions," Environmental Science and Technology, vol. 32, no. 21, pp. 3318-3324, 1998.

[27] G. W. Gee and J. M. Bauder, "Partical-size analysis," in Methods of Soil Analysis, Part 1, A. L. Page, R. H. Miller, and D. R. Keeney, Eds., pp. 383-411, American Society of Agronomy, Madison, Wis, USA, 1986.

[28] L. M. Shuman, "Fractionation method for soil microelements," Soil Science, vol. 140, no. 1, pp. 11-22, 1985.

[29] A. Tessier, P. G. C. Campbell, and M. Blsson, "Sequential extraction procedure for the speciation of particulate trace metals," Analytical Chemistry, vol. 51, no. 7, pp. 844-851, 1979.

[30] H. Tamura, M. Honda, T. Sato, and H. Kamachi, "Pb hyperaccumulation and tolerance in common buckwheat (Fagopyrum esculentum Moench)," Journal of Plant Research, vol. 118, no. 5, pp. 355-359, 2005.

[31] H. Matsufuru, M. Honda, J. Muto, H. Tamura, J. Kojima, and T. Sato, "Remediation and diffusion prevention of lead $(\mathrm{Pb})$ contaminated soil by plants in a pilot test," Journal of Japan Society of Civil Engineering Series G, vol. 63, pp. 51-57, 2007 (Japanese).

[32] M. Katoh, H. Matsuoka, and T. Sato, "Stability of lead immobilized by apatite in lead-containing rhizosphere soil of buckwheat (Fagopyrum esculentum) and hairy vetch (Vicia villosa)," International Journal of Phytoremediation, vol. 17, no. 6, pp. 604611, 2015.

[33] N. T. Basta, R. Gradwohl, K. L. Snethen, and J. L. Schroder, "Chemical immobilization of lead, zinc, and cadmium in smelter-contaminated soils using biosolids and rock phosphate," Journal of Environmental Quality, vol. 30, no. 4, pp. 1222 1230, 2001.

[34] P. Castaldi, L. Santona, and P. Melis, "Heavy metal immobilization by chemical amendments in a polluted soil and influence on white lupin growth," Chemosphere, vol. 60, no. 3, pp. 365-371, 2005.

[35] S. Sauvé, M. McBride, and W. Hendershot, "Soil solution speciation of lead(II): effects of organic matter and $\mathrm{pH}$," Soil Science Society of America Journal, vol. 62, no. 3, pp. 618-621, 1998. 

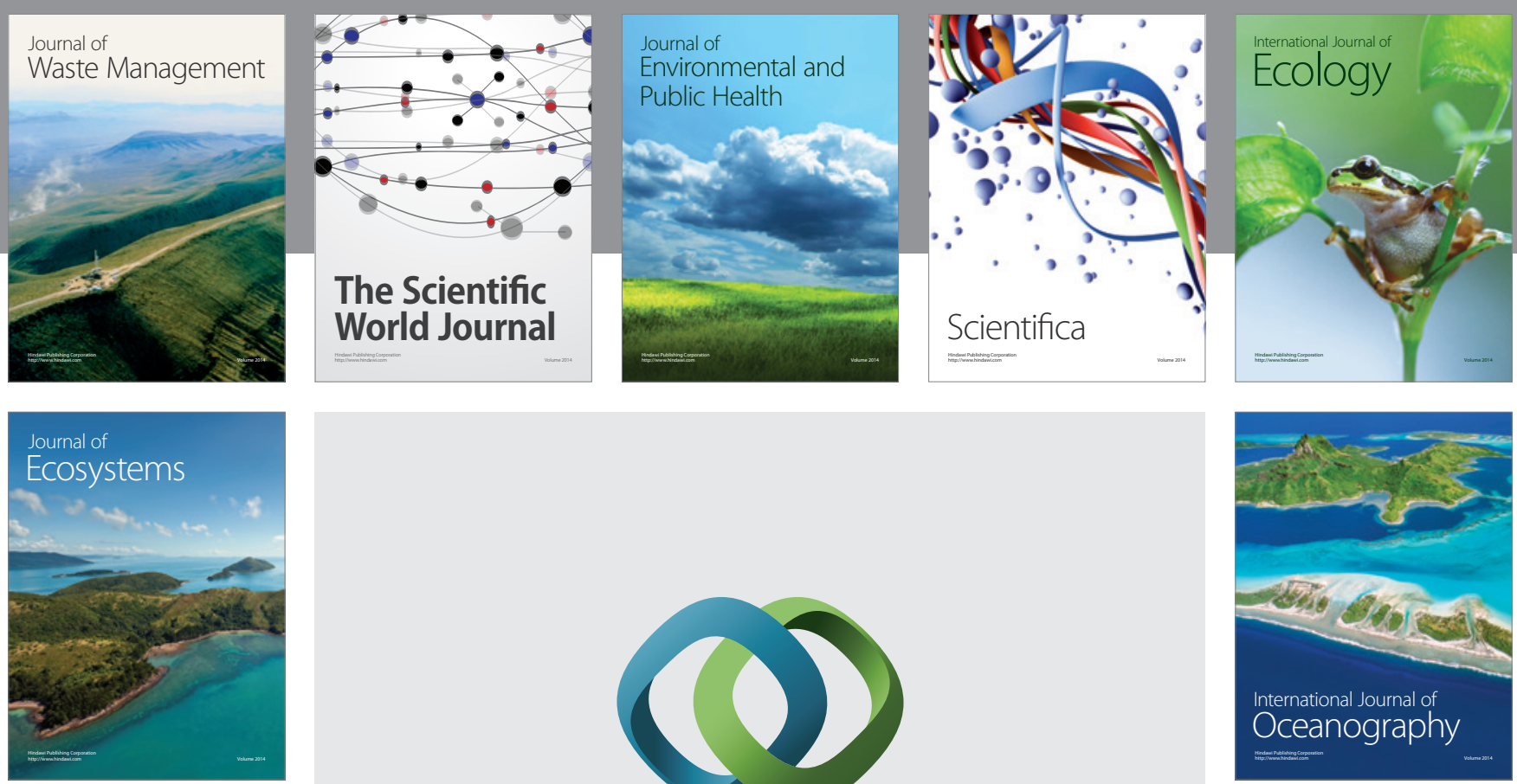

The Scientific World Journal
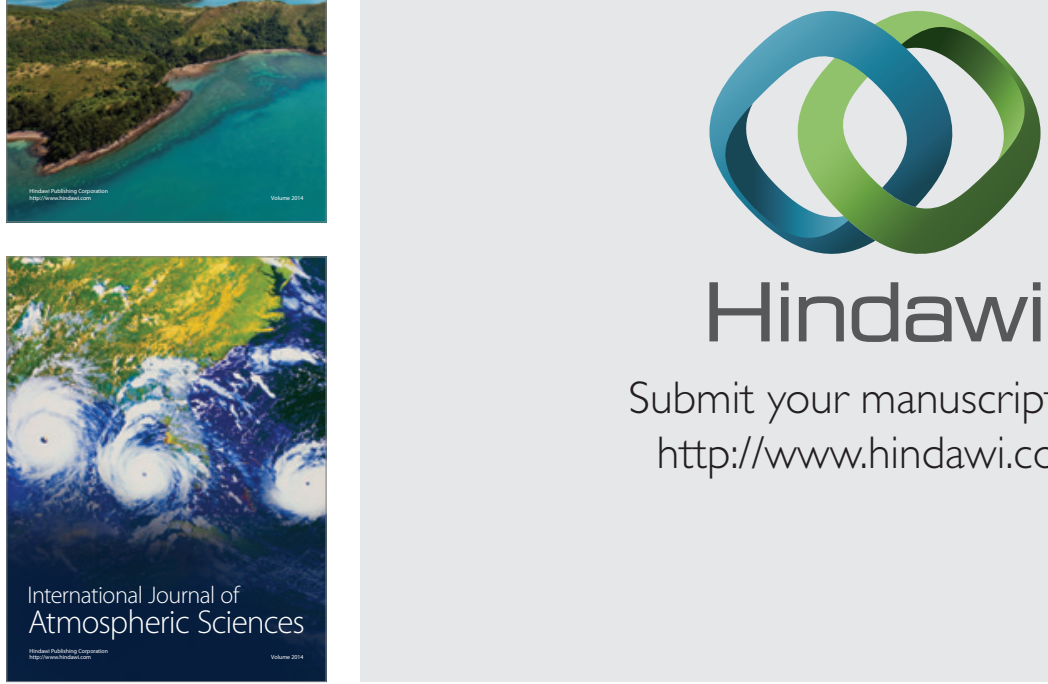

\section{Hindawi}

Submit your manuscripts at

http://www.hindawi.com
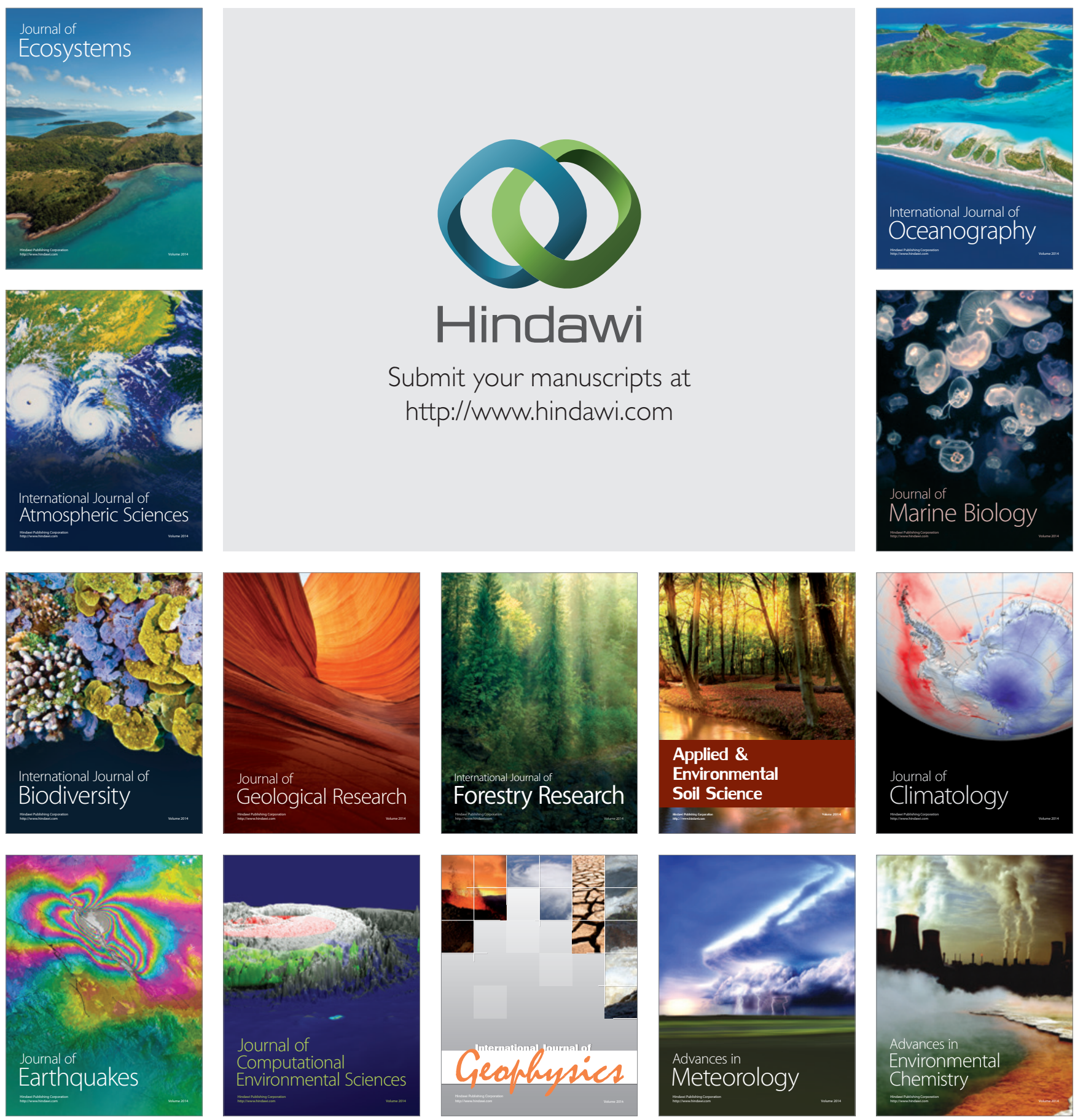